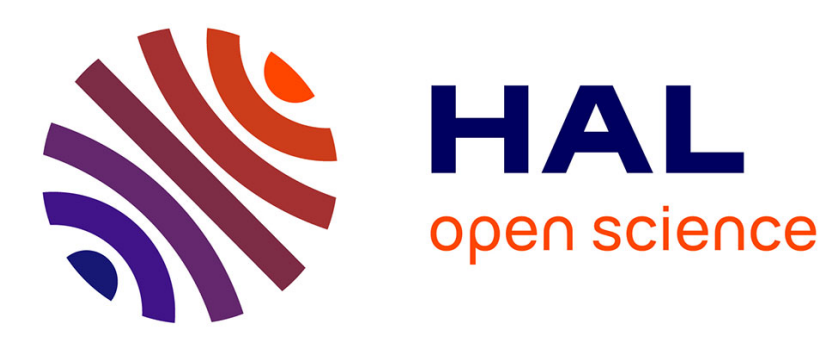

\title{
State Machine-Based Controller for Walk-Halt-Walk Transitions on a Biped Robot
}

\author{
Hayssam Serhan, Patrick Henaff, Chaiban G. Nasr, Fethi Ben Ouezdou
}

\section{To cite this version:}

Hayssam Serhan, Patrick Henaff, Chaiban G. Nasr, Fethi Ben Ouezdou. State Machine-Based Controller for Walk-Halt-Walk Transitions on a Biped Robot. IEEE-RAS International Conference on Humanoid Robots, Humanoids 2008, Dec 2008, Daejeon, South Korea. pp.535-540. hal-00519960

\section{HAL Id: hal-00519960 \\ https://hal.science/hal-00519960}

Submitted on 21 Sep 2010

HAL is a multi-disciplinary open access archive for the deposit and dissemination of scientific research documents, whether they are published or not. The documents may come from teaching and research institutions in France or abroad, or from public or private research centers.
L'archive ouverte pluridisciplinaire HAL, est destinée au dépôt et à la diffusion de documents scientifiques de niveau recherche, publiés ou non, émanant des établissements d'enseignement et de recherche français ou étrangers, des laboratoires publics ou privés. 


\title{
A Based State Machine Controller to Achieve Dynamic Walk - Standup - Walk Cycle of Biped Robot
}

\author{
H. Serhan, P. Hénaff (IEEE Member), C. Nasr (SM IEEE), F. Ouezdou (IEEE Member)
}

\begin{abstract}
In this paper, we show how it is possible to obtain a walk - Standup - walk cycle with a biped robot using only a state machine controller. This work is a continuation of another in which the same approach was used to control the walking gait of the same robot. We introduce four critical angles that affect robot speed and step length. Our control approach consists of two control levels. The low level is a PID controller and the high level is a Dynamic Walking Algorithm, inspired from human locomotion, which tunes the PD controllers and impose the reference signals based on the walking which increases walk stability. This method could be easily implemented in real time because it needs acceptable calculation time. We validated the control approach to a dynamic simulation of our 14DOF biped called ROBIAN. We prove that we can maintain robot walking and stopping stability and walk cycle's repetition without referencing a predefined trajectory or detecting the center of pressure. Results show that the walk of the biped is very similar to human one.
\end{abstract}

\section{INTRODUCTION}

Biorobotics research seeks to develop new robotic technologies modeled after the performance of human and animal neuromuscular systems. These techniques lead to complex control strategies. The implementation of such control approaches in biped walking robot did not enhance the robot locomotion to mimic the human one. In addition, those techniques required many mechanical customization or simplifications. Those customizations contributed to a nonhuman model. However, observation of human walking let one assumes that this walk is seemingly simple. Walking inspiration from human being could be done by trying to mimic natural human locomotion on many different ways. The more common methods are those based on biologically inspired control approaches using neural oscillators as a central pattern generator (CPG) and reflexive control [1][2][3]. The best advantage of this method is its ability to learn through interaction with the environment. However, manual tuning of the oscillators parameters is required. In addition, many parameter optimization techniques were developed. In addition, many parameter optimization techniques were developed, but for the price of increased computational effort along with the increase of the state

H. Serhan is with LISV Laboratory-Versailles $S^{t}$ Quentin UniversityFrance (phone: 961-3-317992; email: hserhan@hotmail.com)

C. Nasr is with the Lebanese University - Faculty of Engineering I Lebanon (phone: 961-3-369245; email: chnasr@ieee.org)

P. Hénaff is with LISV Laboratory-Versailles $S^{t}$ Quentin UniversityFrance (phone: +331.39.25.49.91;email:patrick.henaff@uvsq.fr)

F. B. Ouezdou is with LISV -Versailles $S^{t}$ Quentin University-France (phone: +331.39.25.49.50;email:fethi.benouezdou@uvsq.fr) space dimension. Other method like Passive dynamic walking approach and its extension to active feedback [4][7], [9]-[16] This approach is attractive for its elegance and simplicity, active feedback control is necessary to achieve walking on level ground and varying slopes, robustness to uncertainties and disturbances, and to regulate walking speed, from which we inspired some notion of passive control. Another approach proposed by Sabourin et al. [8], is based on a control strategy that allows the transition of velocities for the dynamic walk of an under actuated twodimensional robot without using a reference trajectory and by simple succession of active and passive phases. Tracking of optimal reference trajectories [17] [18] is based on the analysis of the variations of angles, velocity, and acceleration of human locomotion and trying to reproduce them on robots. This method has many drawbacks. First, to mimic human the robot dimensions should be customized to the model. Secondly this method cannot give the robot the possibility to adapt itself to the surrounding environment.

None of those methods had the possibility to be extended for standing-up the biped robot after a walking cycle and to let the robot walk again after this standing-up phase in a stable way. The work presented in this paper comes after a previous one [29] in which we show how to use a simple description technique based on a Petri-Net algorithm to control a biped robot to walk infinitely without falling, in a similar way to humans. A full comparison between human walking angles and that of our robot was presented and discussed. Here, we propose to mimic human motion based on critical points we extracted from human locomotion in order to control the biped robot to stand-up after a stable and dynamic walking cycle and to let it walk again. Because the proposed technique is not based on following a predefined trajectory, this will give the robot the possibility to adapt itself to the surrounding environment.

This paper is organized as follows: In section II, a description of the control technique is discussed in details along with a description of the robot and the simulator used. In section III, implementation of the control algorithm and the results obtained will be presented in detail. In section IV, a discussion of the results obtained is being developed. This paper concludes with a perspective for further work.

\section{CONTROL APPROACH FOR WALKING}

The proposed control diagram of all the robot actuators is given in Fig.1. It consists of two levels: the low level control designated by the PID controller and the high level control designated by the Dynamic Walking Algorithm, which tunes 
the PD controllers and impose the reference signals based on the walking phase.

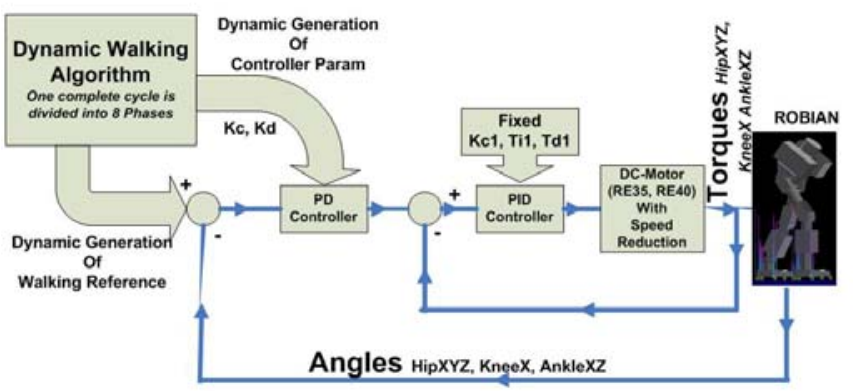

Fig.1. Proposed dynamic control diagram

Our main motivation for bipedal research concerns a significant contribution to the study of human being locomotion system. For this purpose, a multidegree of freedom biped prototype with flexible feet called ROBIAN (Fig.2) has been developed. ROBIAN is composed of two different parts: a locomotion system (lower limbs) and a torso mechanism (upper part). In this paper, we focus only on the locomotion systems. Each leg has a total of seven DoFs [17], [18], three

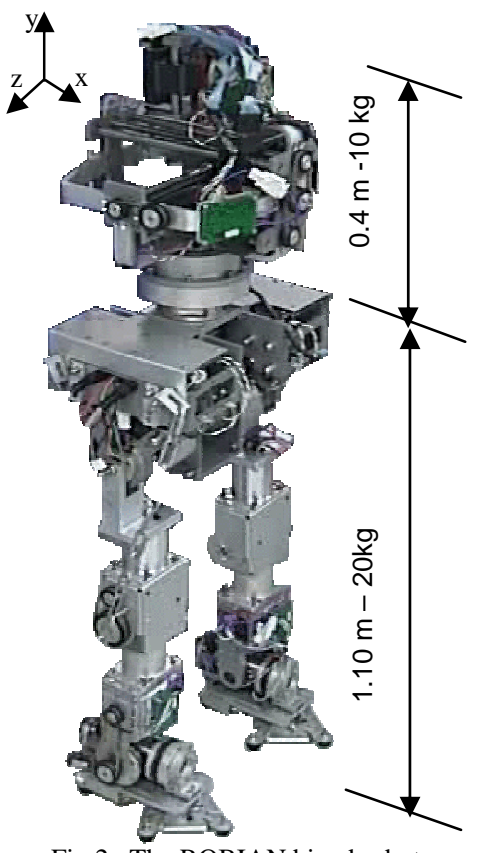

Fig.2. The ROBIAN biped robot actuated DoFs for the hip, one actuated for the knee, two actuated for the ankle and one passive for the foot providing flexible feet. The total height of robot is $1.50 \mathrm{~m}$, its weight is $30 \mathrm{~kg}$, and modular design was developed.

\section{A. Robot walking parameters}

The work on human locomotion done by, Viel [21], Bouisset [22], Allard [23], and Winter [24] allows us to identify the major properties in the human walking that influence step length, velocity, and equilibrium in a dynamic walk. The full human walking cycle described in [21], [22], [23], and [24], can be divided into eight phases. The functionality of each phase can be depicted with respect to one leg acting first as swing leg and then as stance leg (Fig. 2). More description of human walking phase could be found in our previous article [29]. What is important here is that human locomotion is a succession of passive and active phases [8]. In the same manner, the locomotion of our anthropomorphic robot ROBIAN can be characterized by essential angles inspired from the previous description and defined in reference of the movements of the locomotion apparatus of human being in 3 plans (sagital "S", frontal "F" and transversal "T") [25],[26]. These angles could be summarized as follows (Fig. 3) below:

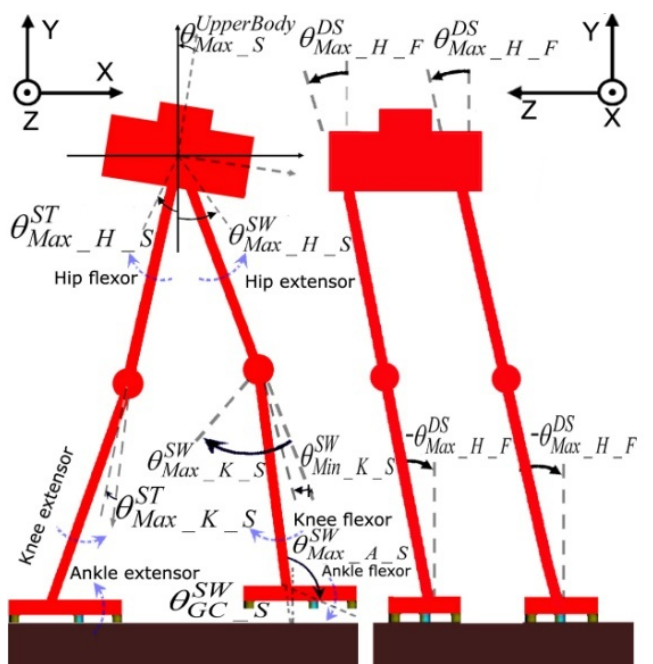

Fig. 3. Extreme angles characterizing ROBIAN Locomotion

In Sagital plan (S plan), two angles that have direct effect on step length, and walk stability are: Swing leg Hip Anterior Extreme Angle: $\theta_{\mathrm{Max}_{-} \mathrm{H}_{-} S}^{\mathrm{SW}}$ and Stance leg Hip Posterior Extreme Angle: $\theta_{\mathrm{Max}_{-} \mathrm{H}_{-} S}^{\mathrm{ST}}$. Four angles that have direct effect on robot dynamics and propulsion are: Swing leg Knee Anterior Extreme Angle $\theta_{\mathrm{Min}_{-} K_{-} S}^{\mathrm{SW}}$, Swing leg Knee Posterior Extreme Angle $\theta_{\mathrm{Max}_{-} K_{-} S}^{S W}$, Stance leg Knee Anterior Extreme Angle $\theta_{\text {Max }_{-} K_{-} S}$, Swing leg Ankle Anterior Extreme Angle: $\theta_{\mathrm{Max}_{-} A_{-} S}^{\mathrm{SW}}$ and Upper Body Inclination Angle: $\theta_{\mathrm{Max}_{-} S}^{\mathrm{UB}}$ has direct effect on robot speed and stability. This is due to its effect on the position of the robot CoM. Based on the swing leg Tibia Ground Contact Angle $\theta_{G C_{-} S}^{S W}$, the control unit should regulate the lift off phase of the upcoming swing leg.

In Frontal Plan (F plan), two angles have direct effect on robot stability are: Maximum Hip ABduction Angle: $\theta_{\mathrm{Max}_{-} \mathrm{H}_{-} \mathrm{F}}^{\mathrm{DS}}$ and Maximum Hip ADduction Angle: $-\theta_{\mathrm{Max}_{-} \mathrm{H}_{-} F}^{\mathrm{DS}}$.

Notice that, in Transversal Plan ( $T$ plan), we are not taking into account hip movement because internal rotation movement of the human leg is negligible. We assume that the leg is not doing any rotation.

\section{B. PD Controllers parameters}

It should be noticed that all the motors are drove by PD controllers with the predefined angles as desired angles. A general equation of each PD controller of each actuator $\tau$ is given below:

$\tau_{\text {Actuator }}^{\text {Leg }}=K c_{\text {Actuator }}^{\text {Phase }} *\left(\theta_{d}-\theta_{\text {Actuator }}^{\text {Leg }}\right)+K d_{\text {Actuator }}^{\text {Phase }} *\left(\dot{\theta}_{d}-\dot{\theta}_{\text {Actuator }}^{\text {Leg }}\right)$

Where: $\theta_{d}$ and $\dot{\theta}_{d}$ are the desired angle and velocity values. Leg corresponds to Stance or Swing leg. Phase corresponds to one of the eights walking phases described in [21],[22], [23],[24]. Actuator corresponds to Hip, Knee and Ankle. Plan corresponds to Sagital, Frontal, and Transversal. In our 
approach robot speed is controlled by simple variation of $\theta_{\mathrm{Max}_{-} \mathrm{S}}^{\mathrm{UB}}$ and $\theta_{\mathrm{Min}_{-} \mathrm{K}_{-} S}^{\mathrm{SW}}$ as described in [29], and the values of Kc, Kd parameters are changed at each phase.

\section{Inspired Control strategy (Walking Phase)}

In our control strategy described in details in [29], the control algorithm is divided into 12 states. States $1,3,4,5,6,10$ correspond to the swing leg and states 2,7,8,9,11 correspond to the stance leg. They will actually happen in the same time if right \& left leg motion during a half walking cycle is studied. The initial position is defined when the two legs are in contact with ground and the robot is standing up but one of the legs is behind the other. Applying techniques inspired from human locomotion, Robian dynamic walk can be modeled with a Petri Net Algorithm (Fig. 4).

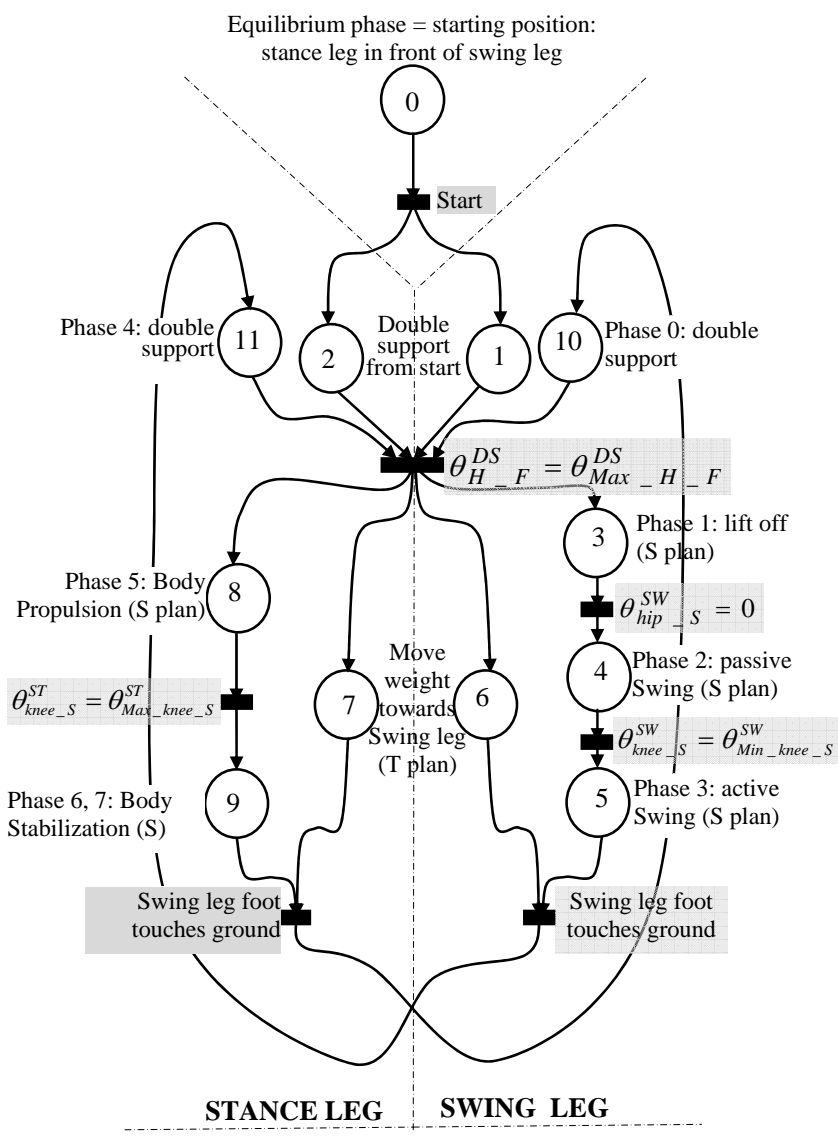

Fig. 4. Petri Net Algorithm for Robian Dynamic Walk (S_Plan or Sagital Plan, F_Plan or Frontal Plan)

With this control approach, we obtained previously a infinite walking cycle with a dynamic simulation of ROBIAN builded under OpenHRP (Open Architecture Humanoid Robotics Platform) . Fig 5 shows the superposition of ten successive walking phases extracted from a long walk of the biped [29].

The correspondence between the Petri Net Algorithm states and the human walking phases are detailed in [29].

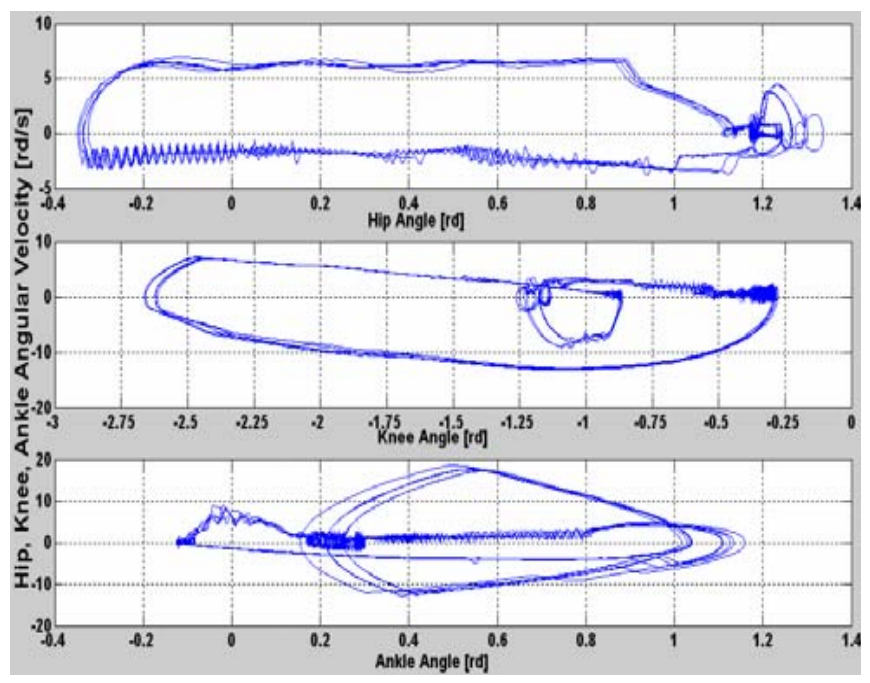

Fig.5. Phase succession for ten walking cycles (angular velocity of Hip, Knee and ankle function of their corresponding angle)

\section{CONTROL STRATEGY FOR STOP AND WALK CYCLE}

In order to stop ROBIAN walk cycle and keep it in a standup stable position, we modified our algorithm in order to introduce a stop phase. This algorithm will start after swing leg touches ground (State 9 in Fig. 4.). Where we swap stance and swing leg. Starting this point we extend the Stance leg Knee to its maximum in order to propagate the robot forward, same for Swing Leg Knee, so that Swing leg feet will touche ground in approximately the same position as that of the Stance leg. From this point, we start extending upper body by activating right and left hip motors, so that the upper body will be in a vertical position. Left and right ankle motors will be activated in order to follow their corresponding hip angles and therefore keep robot upper body parallel to ground. Once Swing leg feet touches ground, we continue the same process till all corresponding angles reach their destination, and after that we control all robot motors in order to memorize the reached positions. At this time, the robot is in stable standup position for which the distance between right and left legs foot is low. Then, the robot stops and remains standing up in a stable position. From this position we can control the robot to walk again by simple reapplying our walking control techniques previously described in II.C. This contributed to a stable walk-standupwalk cycle.

\section{A. States description}

State 12: (Swing Leg - S Plan) "Lift-Off \& Passive Swing State". It starts after the Stop Switch is activated. At that position most Body weight is applied on Stance leg. During this State, three actions happen in parallel:

1. Apply an active torque to the Hip for accelerate slowly the dynamic move of the oscillatory leg and create body inertial effects until thigh is in vertical position:

$$
\tau_{H_{-} S}^{S W}=K c_{H_{-} S}^{3} *\left(\theta_{M a L_{-} H_{-} S}^{S W}-\theta_{H_{-} S}^{S W}\right)+K d_{H_{-} S}^{3} *\left(\dot{\theta}_{M a x_{-} H_{-} S}^{S W}-\dot{\theta}_{H_{-} S}^{S W}\right)
$$

2. Extend Knee:

$$
\tau_{K_{-} S}^{S W}=K c_{K_{-} S}^{3} *\left(\theta_{M i n_{-} K_{-} S}^{S W}-\theta_{K_{-} S}^{S W}\right)+K d_{K_{-} S}^{3} *\left(\dot{\theta}_{M i n_{-} K_{-} S}^{S W}-\dot{\theta}_{K_{-} S}^{S W}\right)
$$


3. Activate Ankle for keeping feet parallel to ground: $\tau_{A_{-} S}^{S W}=K c_{A_{-} S}^{3} *\left(\theta_{\text {Max_A_S }}^{S W}-\theta_{A_{-} S}^{S W}\right)+K d_{A_{-} S}^{3} *\left(\dot{\theta}_{M a \alpha_{-} A_{-} S}^{S W}-\dot{\theta}_{A_{-} S}^{S W}\right)$

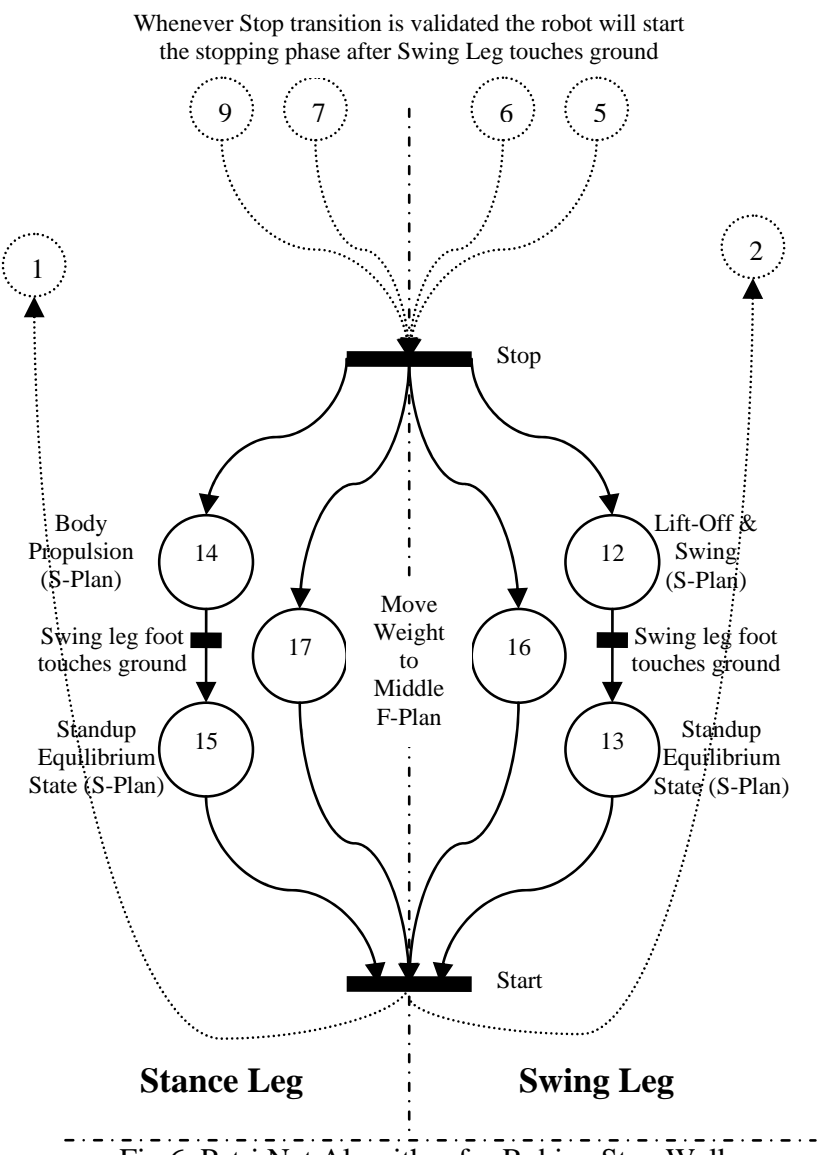

Fig.6. Petri Net Älgorithm for Robian Stop Walk

State 14: (Stance Leg - S Plan) "Body Propulsion State”. It starts after the Stop Switch is activated. Here we extend Knee for moving body forward. During this state, three actions happen in parallel:

1. Hip is activated for stabilizing upper body:

$$
\tau_{H_{-} S}^{S T}=K c_{H_{-} S}^{5} *\left(\theta_{\text {Max }-}^{U B}-\theta_{H_{-} S}^{S T}\right)+K d_{H_{-} S}^{5} *\left(\dot{\theta}_{\text {Max_ } S}^{U B}-\dot{\theta}_{H_{-} S}^{S T}\right)
$$

2. Extend Knee for moving body forward:

$$
\tau_{K_{-} S}^{S T}=K_{K_{-} S}^{5}{ }^{*}\left(\theta_{\text {Max }}^{S T} K_{-} S-\theta_{K_{-} S}^{S T}\right)+K d_{K_{-}}^{5} S *\left(\dot{\theta}_{\text {Max }}^{S T} K_{-} S-\dot{\theta}_{K_{-} S}^{S T}\right)
$$

3. Keep Ankle free:

$$
\tau_{A_{-} S}^{S T}=0
$$

State 13: (Swing Leg - S Plan) "Standup Equilibrium State". It starts after the Swing Leg touches ground. Here we try to memorize the last position values. During this state, three actions happen in parallel:

1. Apply an active torque to Hip for maintaining upper body in a vertical position:

$$
\tau_{H_{\_} S}^{S W}=K c_{H_{-} S}^{3} *\left(\theta_{M a{ }_{-} H_{-} S}^{S W}-\theta_{H_{-} S}^{S W}\right)+K d_{H_{-} S}^{3} *\left(\dot{\theta}_{M a \chi_{-} H_{-} S}^{S W}-\dot{\theta}_{H_{-} S}^{S W}\right)
$$

2. Stabilize Knee:

$$
\tau_{K_{-} S}^{S W}=K c_{K_{-} S}^{3} *\left(\theta_{M i n_{-} K_{-} S}^{S W}-\theta_{K_{-} S}^{S W}\right)+K d_{K_{-} S}^{3} *\left(\dot{\theta}_{M i n_{-} K_{-} S}^{S W}-\dot{\theta}_{K_{-} S}^{S W}\right)
$$

3. Stabilize Ankle:

$$
\tau_{A_{-} S}^{S W}=K c_{A_{-} S}^{3} *\left(\theta_{\text {Max }_{-} A_{-} S}^{S W}-\theta_{A_{-} S}^{S W}\right)+K d_{A_{\_} S}^{3} *\left(\dot{\theta}_{M_{1} x_{-} A_{-} S}^{S W}-\dot{\theta}_{A_{-} S}^{S W}\right)
$$

State 15: (Stance Leg - S Plan) "Standup Equilibrium State”. It starts after the Swing Leg touches ground. Here we try to memorize the last position values. During this state, three actions happen in parallel:

1. Apply an active torque to Hip for maintaining upper body in a vertical position (here we apply an active torque opposite to that applied and the Swing Leg for stabilizing \& counteracting the torque applied on the swing leg):

$$
\tau_{H_{-} S}^{S T}=K c_{H_{-} S}^{5} *\left(\theta_{M x_{-} S}^{U B}-\theta_{H_{-} S}^{S T}\right)+K d_{H_{-} S}^{5} *\left(\dot{\theta}_{M a x_{-} S}^{U B}-\dot{\theta}_{H_{-} S}^{S T}\right)
$$

2. Stabilize Knee:

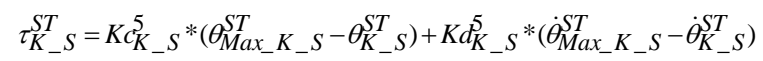

3. Stabilize Ankle:

$\tau_{A_{-} S}^{S T}=0$

State 16: (DS - F Plan) Move Weight to Middle position. During this state, two actions happen in parallel:

1. Apply an active torque to Hip for maintaining upper body in a vertical position:

$\tau_{H_{-} F}^{S W}=K c_{H_{-} F}^{0} *\left(\theta_{\text {Max } H_{-} F}^{D S}-\theta_{H_{-} F}^{S W}\right)+K d_{H_{-} F}^{0} *\left(\dot{\theta}_{\text {Max_ } H_{-} F}^{D S}-\dot{\theta}_{H_{-} S}^{S W}\right)$

2. Activate Ankle in order to follow the inverse of the current Hip angle, this will lead to maintaining body parallel to ground:

$$
\tau_{A_{-} F}^{S W}=K c_{A_{-} F}^{0} *\left(-\theta_{H_{-} F}^{S W}-\theta_{A_{-} F}^{S W}\right)+K d_{A_{-} F}^{0} *\left(-\dot{\theta}_{H_{-} F}^{S W}-\dot{\theta}_{A_{-} F}^{S W}\right)
$$

State 17: (DS - F Plan) Move Weight to Middle position. During this State, two actions happen in parallel:

1. Apply an active torque to Hip for maintaining upper body in a vertical position (here we apply an active torque opposite to that applied and the Swing Leg for stabilizing \& counteracting the torque applied on the swing leg):

$\tau_{H_{-} F}^{S T}=K c_{H_{-} F}^{4} *\left(\theta_{\text {Max } H_{-} F}^{D S}-\theta_{H_{-} F}^{S T}\right)+K d_{H_{-} F}^{4} *\left(\dot{\theta}_{M a x_{-} H_{-} F}^{D S}-\dot{\theta}_{H_{-} S}^{S T}\right)$

2. Activate Ankle in order to follow the inverse of the current Hip angle:

$\tau_{A_{-} F}^{S T}=K c_{A_{-} F}^{4} *\left(-\theta_{H_{-} F}^{S T}-\theta_{A_{-} F}^{S T}\right)+K d_{A_{-} F}^{4} *\left(-\dot{\theta}_{H_{-} F}^{S T}-\dot{\theta}_{A_{-} F}^{S T}\right)$

\section{B. Implementation of control Algorithm on simulated ROBIAN biped}

We applied our algorithm on a simulated model of our biped robot ROBIAN developed in the LISV Laboratory University of Versailles in France. Because LISV is involved in the Joint Japanese-French Robotics Laboratory (JRL), the simulator used in this work is OpenHRP (Open Architecture Humanoid Robotics Platform), which is a software platform for dynamic simulation of humanoid robots, developed by AIST, the University of Tokyo and MSTC. The OpenHRP model of the ground/foot contact is based on a spring-damper system. In our simulation, the parameters $\mathrm{Kp}$ (spring coefficient) and $\mathrm{Cp}$ (damper coefficient) are calculated experimentally:

- Spring-damper coefficients parallel to axis [X, Y, Z]: $K_{P}=\left[10^{5}, 10^{5}, 10^{5}\right]$ in $\mathrm{N} / \mathrm{m} ; C_{P}=\left[10^{4}, 10^{4}, 10^{4}\right]$ in $\mathrm{N} /(\mathrm{m} / \mathrm{sec})$;

- Spring-damper coefficients rotational around axis [X,Y,Z]: $K_{R}=\left[1.610^{4}, 10^{3}, 10^{3}\right]$ in $\mathrm{Nm} / \mathrm{rad}$;

$C_{R}=\left[1.610^{3}, 10^{2}, 10^{2}\right]$ in $\mathrm{Nm} /(\mathrm{rad} / \mathrm{sec})$;

ROBIAN foot contains 5 similar plots in rubber. Static and sliding friction factors are: Static $=0.6$, sliding $=0.5$. 


\section{Simulation results}

Walking speed and stability is primary influenced by four parameters: $\theta_{\text {Max }_{-} S}^{\mathrm{UB}}$ affects the robot center of mass position. $\theta_{\mathrm{Max}_{-} H_{-} S}^{S W}, \theta_{\mathrm{Max}_{-} K_{-} S}^{\mathrm{Stann}}$ and $\theta_{\mathrm{Min}_{-} \text {knee_xy }}^{\mathrm{SW}}$ affect the step length and body propulsion velocity. So, with a simple variation of those four reference angle values, the step length and hence the walking speeds of the robot are controlled [29]. Walking snapshots from 3D space are represented on Fig. 7. In this simulation we are showing the progression of the walking cycle, from Stand-up right leg in front of left leg to walk to standup left and right leg are in the same position to walking again. Because our aim is to more understand human being locomotion, our biped robot was designed in an anthropomorphic way. Then it could reproduce human gaits with its lower part [18]. This is very important in medical applications, where we need to test different kind of prosthesis on robot before implementing them on humans.

Finally, the results obtained rely on the fact that ROBIAN was able to walk infinitely into the simulator without falling [29]. This is due to the continuous control of the PD controllers parameters based on the walking phases, thus based on the joint positions. In order to implement the control algorithm on the real robot ROBIAN, the technological limits of the actuators has been taken into account. First, the power consumption analysis issued from those motors was within the real limits. Then, the value of the motor velocity reduction is changed in order to have the maximum velocity and maximum torque for each motor under the values specified into the datasheet. Stability margin for different referenced angles is summarized in the Table II. In Fig. 8 we are showing the joints angle variations for hip, knee and ankle of left and right legs. In Fig.9 we are showing the speed variation of the robot, taking into consideration that the stop phase will start at $\mathrm{T}=2 \mathrm{sec}$, and finishes at $\mathrm{T}=8$ secs.

\section{DISCUSSION AND CONCLUSION}

We achieved our goal in making in simulation the ROBIAN robot walk, Stop and then walk again in 3D. We approached the human walking angles without a lot of complexity in the control. ROBIAN foot has a passive and adjustable flexibility, which highlight the necessity of active and flexible feet. Also the feet land parallel to ground, the swinging leg will have the foot moving as human in the beginning of the swing phase. In passive swing phase, ankle motors were controlled in order to keep the foot parallel to ground. In the active swing phase, the foot was stabilized in this position in order to hit the ground in a way so that the ground reaction forces will be distributed equally on the five foot plots. In order to approach the smoothness of human neuromuscular commands, a muscle model created by Serhan et al. [28] is added to ROBIAN low level control stage. This model is based on a PID controller and a DC motor. Hence, it will be easily integrated into our control diagram without making any changes, neither to the underlying hardware system nor to the high level control algorithm (Dynamic Walk Algorithm). This integration shall add active compliance. Also this technique is not very consuming in processing time (algorithm execution time is about $8 \mathrm{~ms}$ on a Pentium IV processor running at $3.0 \mathrm{Ghz}$ with 1 GB RAM), so it could be implemented in real-time.

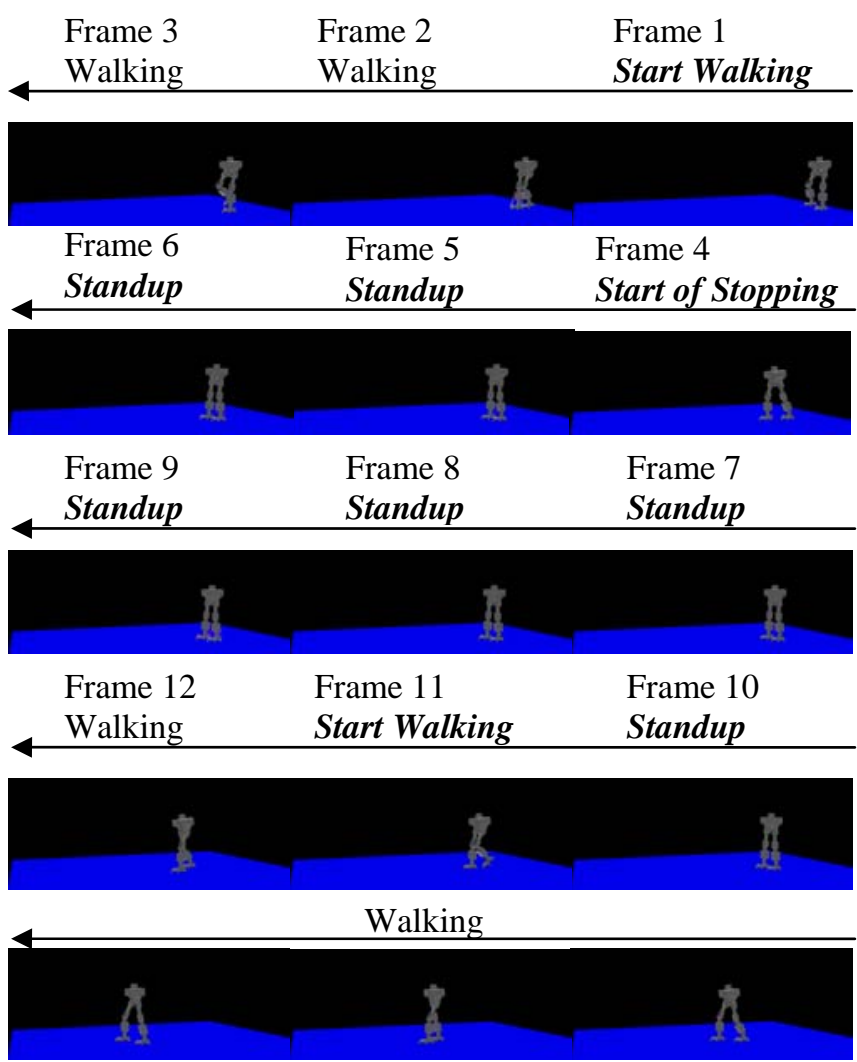

Fig.7. Walking snapshots in 3D for Walk-Standup-Walk cycle. Frames captured from right to left. Time between each snapshot for Frames from 1 to 5 is $500 \mathrm{~ms}$. Time between each snapshot for Frames from 5 to 10 is $1000 \mathrm{~ms}$
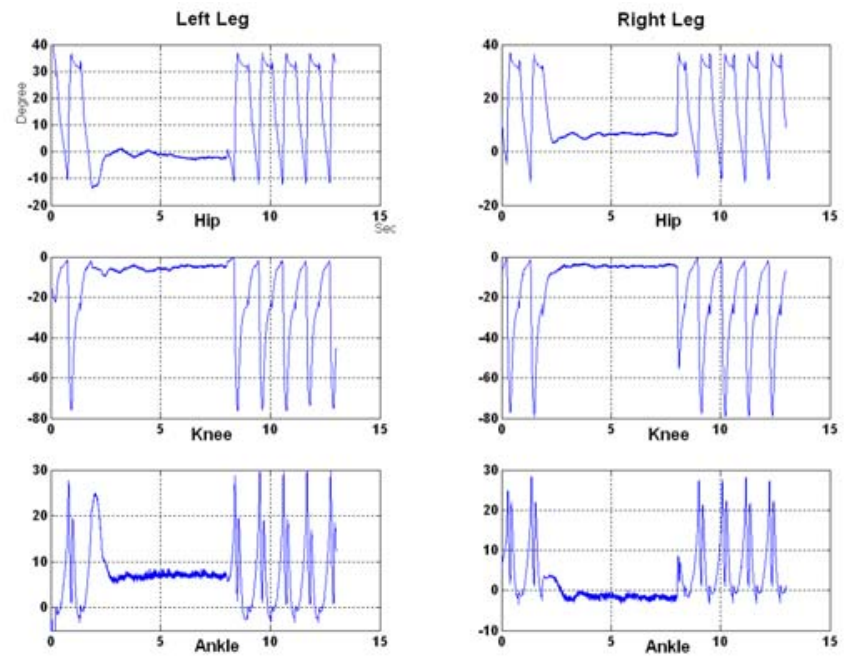

Fig.8. graphs for hip, knee, and ankle Walking-Stop-Walking angles of ROBIAN for two walking cycles at Start, Stop Period (2 to $8 \mathrm{~s}$ ) and 4 walking cycles after.

This work was a first step in our study. We are working now to validate our approach on the real biped ROBIAN. A next work will concern perturbations effects on robot stability during the walking phase and the stop phase on irregular terrain. The third step concerns implementing our 
muscle model [28] in ROBIAN for introducing active compliance. In conclusion, the proposed approach, allows us to achieve Robian dynamic walking and standup similar to human being.

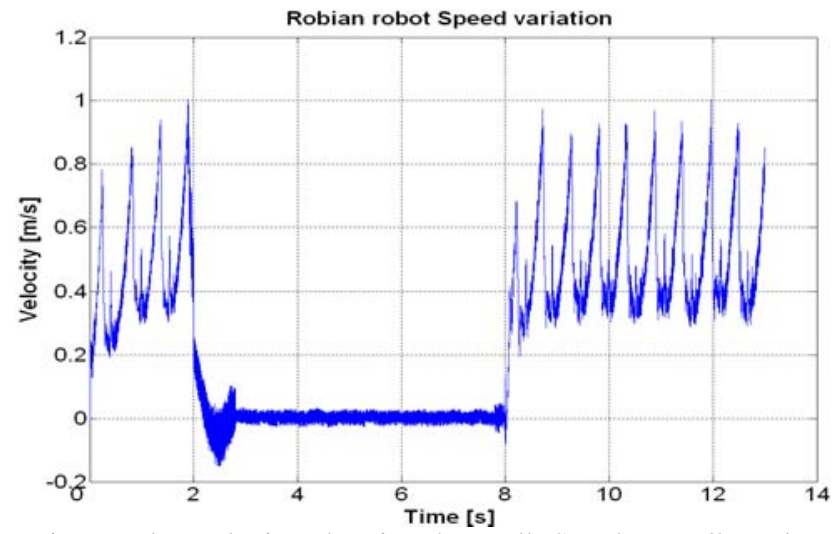

Fig.9. Robot velocity, showing the Walk-Standup-Walk cycles

Table II

Stability Limit Margins

\begin{tabular}{|c|c|c|c|c|c|}
\hline \multicolumn{2}{|c|}{$\theta_{M a x_{-} H_{-}}^{S W}$} & \multicolumn{2}{|c|}{$\theta_{\text {Max_H_S }}^{S T}$} & \multicolumn{2}{|c|}{$\theta_{M i n \_K}^{S W}{ }_{-S}$} \\
\hline $\begin{array}{l}\text { Acceptable } \\
\text { margin }\end{array}$ & $\begin{array}{l}\text { Currently } \\
\text { allocated }\end{array}$ & $\begin{array}{c}\text { Acceptable } \\
\text { margin }\end{array}$ & $\begin{array}{l}\text { Currently } \\
\text { allocated }\end{array}$ & $\begin{array}{c}\text { Acceptable } \\
\text { margin }\end{array}$ & $\begin{array}{l}\text { Currently } \\
\text { allocated }\end{array}$ \\
\hline $20^{\circ}$ to $40^{\circ}$ & $30^{\circ}$ & $-20^{\circ} t o-10^{\circ}$ & $-15^{\circ}$ & $-30^{\circ}$ to $-2^{\circ}$ & $-4^{\circ}$ \\
\hline \multicolumn{2}{|c|}{$\theta_{M_{-}{ }^{S W}{ }_{-} S}$} & \multicolumn{2}{|c|}{$\theta_{\text {Max_K__S }}^{S T}$} & \multicolumn{2}{|c|}{$\theta_{\text {Max_A_S }}^{S W}$} \\
\hline $\begin{array}{c}\text { Acceptable } \\
\text { margin }\end{array}$ & $\begin{array}{l}\text { Currently } \\
\text { allocated }\end{array}$ & $\begin{array}{l}\text { Acceptable } \\
\text { margin }\end{array}$ & $\begin{array}{l}\text { Currently } \\
\text { allocated }\end{array}$ & $\begin{array}{c}\text { Acceptable } \\
\text { margin }\end{array}$ & $\begin{array}{l}\text { Currently } \\
\text { allocated }\end{array}$ \\
\hline$-85^{\circ}$ to $-55^{\circ}$ & $-75^{\circ}$ & $0^{\circ}$ to $50^{\circ}$ & $35^{\circ}$ & $0^{\circ}$ to $50^{\circ}$ & $35^{\circ}$ \\
\hline \multicolumn{2}{|c|}{$\overline{\theta_{\text {Max_S }}^{U B}}$} & \multicolumn{2}{|c|}{$\theta_{M_{2}{ }^{D S}{ }_{-} F}$} & & \\
\hline $\begin{array}{l}\text { Acceptable } \\
\text { margin }\end{array}$ & $\begin{array}{l}\text { Currently } \\
\text { allocated }\end{array}$ & $\begin{array}{c}\text { Acceptable } \\
\text { margin }\end{array}$ & $\begin{array}{l}\text { Currently } \\
\text { allocated }\end{array}$ & & \\
\hline $0^{\circ}$ to $18^{\circ}$ & $6^{\circ}$ & $0^{\circ}$ to $10^{\circ}$ & $4^{\circ}$ & & \\
\hline
\end{tabular}

\section{REFERENCES}

[1] G. Taga, Y.Yamaguchi, H. Shimizu, "Self-organized control of bipedal locomotion by neural oscillators in unpredictable environment," Biological Cybernetics 65,1991, 147-159

[2] G. Endo, J. Morimoto, J. Nakanishi, G. Cheng, "An empirical exploration of a neural oscillator for biped locomotion control,” IEEE, Int. Conference on Robotics and Automation, 2004, pp. 3036-3042

[3] T. Matsubara, J. Morimoto, J. Nakanishi, M. Sato, K. Doya, "Learning CPG-based biped locomotion with a policy gradient method,” Robotics and Autonomous Systems 54 ,2006, 911-920

[4] M.Garcia, A. Chatterjee, A. Ruina, and M. Coleman, "The simplest walking model: Stability, complexity, and scaling," ASME J. Biomechan. Eng., vol. 120, no.2, pp. 281-288, 1998.

[5] A. Goswami, B. Espiau, and A. Keramane, "Limit cycles in a passive compass gait and passivity-mimicking control laws," Autonomous Robots, vol. 4, no. 3, pp. 273-286, 1997.

[6] A. Goswami, B. Thuilot, and B. Espiau, "A study of the passive gait of a compass-like biped robot: Symmetry and chaos,” I. J. Robot. Res., vol. 17, no. 12, pp. 1282-1301, 1998.

[7] T. McGreer, "Passive dynamic walking," Int. J. Robot, Res., vol. 9, no. 2, pp. 62-82, 1990.

[8] C. Sabourin, O. Bruneau, J-G. Fontaine. "Pragmatic rules for realtime control of the dynamic walking of an under-actuated biped robot,” Proc. IEEE Conf. on Rob. and Automation, 2004, 4216-4221

[9] H. Ohta, M. Yamakita, and K. Furuta, " From Passive to active dynamic walking," in Proc. IEEE Conf. Decision Control, Phoenix, AZ, Dec.1999, pp.3883-3885.

[10] M.W. Spong, "Bipedal locomotion, robot gymnastics, and motor air hockey: A rapprochement,” in Proc. TITech COE/Super MechanoSystems workshop, Tokyo, Japan, Feb. 1999, pp. 34-41.
[11] M.W. Spong, "Passivity based control of the campass gait biped," in Proc. IFAC Trienmial World Congr., Beijing, China, vol. 3, July 1999, pp. 19-23.

[12] A.D. Kuo, "Stabilization of lateralmotion in passive dynamic walking,” Int. J. Robot. Res., vol. 18, no. 9, pp. 917-930, 1999.

[13] S.H. Collins, M. Wisse, and A. Ruina, "A three-dimensional passive dynamic walking robot with two legs and knees,” Int. J. Robot. Res., vol. 20, 4, no. 3, pp. 273-286, 1997.

[14] M.w. Spong and F. Bullo, "Controlled symmetrics and passive walking,”IEEE trans. Aut. Contr., vol. 50, no. 7, pp. 1025-1031, 2005.

[15] A.D. Ames, R.D. Gregg, E.D.B. Wendel, and S. Sastry, "Towards the geometric reduction of controlled three-dimensional robotic bipedal walkers," in Proc. Workshop Lagrangian Hamiltonian Methods Nonlinear Control, Nagoya, Japan, July 2006, pp. 117-124.

[16] M.W. Spong and G. Bhatia, "Further results on control pf the compass gait biped,” in Proc. IROS 2003, Las Vegas, Nevada, 27-30 Oct.. 2003, pp. 1933-1938.

[17] A. Konno, R. Sellaouti, F.B. Amar, and F.B. Ouezdou. "Design and development of the biped prototype ROBIAN”. In IEEE Int. Conf. on Rob. and Aut. (ICRA), D.C., U.S.A., 2002, pp. 1384-1389.

[18] R. Sellaouti and F. B. Ouezdou, Design and control of a 3DOFs parallel actuated mechanism for biped application, Mechanism and Machine Theory, Volume 40, №12, pages 1367-1393, decembre 2005.

[19] C Chevallereau, Y Aoustin, Optimal reference trajectories for walking and running of a biped robot, Robotica 19 (2001), pp. 557-569.

[20] Z. Tang, Z. Sun, C. Zhou and L. Hu, "Reference Trajectory Generation for 3-Dimensional Walking of a Humanoid Robot" Tsinghua Science \& Technology Volume 12, Issue 5, October 2007, Pages 577-584

[21] E.Viel, "La marche humaine, la course et le saut," Masson, 2000.

[22] S. Bouisset, B. Maton, "Muscles, posture et mouvement," Hermann, 1995.

[23] P. Allard, J.-P. Blanchi., "Analyse du mouvement humain par la biomécanique,” 2000, Décarie.

[24] D. Winter, "Biomechanics and Motor Control of Human Movement," Third Edition, Wiley 2005.

[25] Bouchet A., Cuilleret J., "Anatomie topographique, descriptive et fonctionnelle”, T3b le membre inférieur. SIMEP 3rd ed. 1997

[26] Kapandji I., "Physiologie articulaire, tome Membre inférieur", Maloine, 5th edition, 1999

[27] C. Williams, "Tuning a PID Temperature Controller," http://newton.ex.ac.uk/teaching/CDHW/Feedback/Setup-PID.html.

[28] Serhan H., Nasr C., Henaff P., "Designing a Muscle Like System Based on PID Controller and Tuned by Neural Network",IEEE WCCI Congress, Vancouver, 2006,pp. 10090-10097

[29] Serhan H., Nasr C., Henaff P., BenOuezdou F., "A New Control Strategy for ROBIAN Biped Robot Inspired from Human Walking”, to appear in Proc. IEEE of IROS 2008, Nice. 